\title{
METHODS \& DESIGNS Lexical ambiguity of words used in English text
}

\author{
BRUCE K. BRITTON \\ University of Georgia, Athens, Georgia 30602
}

\begin{abstract}
Lexical ambiguity is generally assumed to be widespread in natural languages but quantitative estimates have not been available. At least $32 \%$ of the words used in English text were found to be ambiguous in studies reported here. This figure is probably very conservative. Temporary word definitions established for special purposes occurred in $30 \%$ of a sample of texts.
\end{abstract}

This paper is concerned with lexical ambiguity, ambiguity that occurs when a word has more than one meaning. For example, in "The soldiers liked the port," the word port can refer to a wine or a harbor.

In the literature on language processing, it is widely assumed that natural languages are ambiguous (Garrett, 1970). Substantial amounts of theoretical and experimental work have been devoted to models of word and sentence processing to account for the resolution of lexical ambiguity. Apparently, no quantitative estimate of the amount of lexical ambiguity has been attempted.

Of particular interest is the frequency of ambiguity among words most commonly used in discourse. Rare words are less interesting. If a word is used rarely, it contributes little to the ambiguity encountered by language processors. About $41 \%$ of the words appearing in Kucera and Francis' (1967) word frequency count occurred only once in the million-word sample. All of these words combined constitute only $2 \%$ of the words used in English text.

If lexical ambiguity is extensive among words used in English text discourse, as has been generally assumed, then further investigation of processing mechanisms for resolving ambiguity may be warranted. If there is relatively little lexical ambiguity among the words commonly used in English text, then research attention might better be directed elsewhere. In this paper, lower bounds are determined for the amount of lexical ambiguity of words used in English text, two special types of ambiguity are described and quantified, and a refined method for quantifying the ambiguity of individual lexical units is presented.

\section{STUDY 1}

As a preliminary step, the ambiguity of a random sample of English words was determined.

The encouragement and support of Rudolph W. Schulz of the University of lowa is gratefully acknowledged. The author would like to thank Ellen Gagné and Stuart Katz of the University of Georgia, and Larry Jacoby, then of Iowa State University, for their helpful comments on earlier versions of this paper. Appreciation is due to Professor James V. Hinrichs for making the judgments for Study 6 .

\section{Method}

Word definitions in the American Heritage Dictionary of the English Language (1969) were examined. A sample of 12 page numbers was drawn by unsystematically choosing six numbers of three-digit lengths and six numbers consisting of four digits from a table of random numbers. Independently, the first or second column on each page was selected randomly. A total of 257 words comprised the final sample. Within the entry for each word, each meaning with a separate number was counted separately. Meanings marked regional, archaic, or slang, and abbreviations were excluded from the analysis.

In cases where the word was of two parts of speech listed under separate entries, meanings that were similar for the two were excluded.

\section{Results and Discussion}

Figure 1 shows the frequency of the various numbers of meanings for the 257 words. The distribution of meanings per word is markedly skewed. The number of meanings ranges from 1 to 30 , and there is more than one meaning for $44 \%$ of the words.

A random sample of words is not representative of words commonly used in discourse, so the sample included many words that are rarely used in written or spoken discourse. Estimates of ambiguity based on such

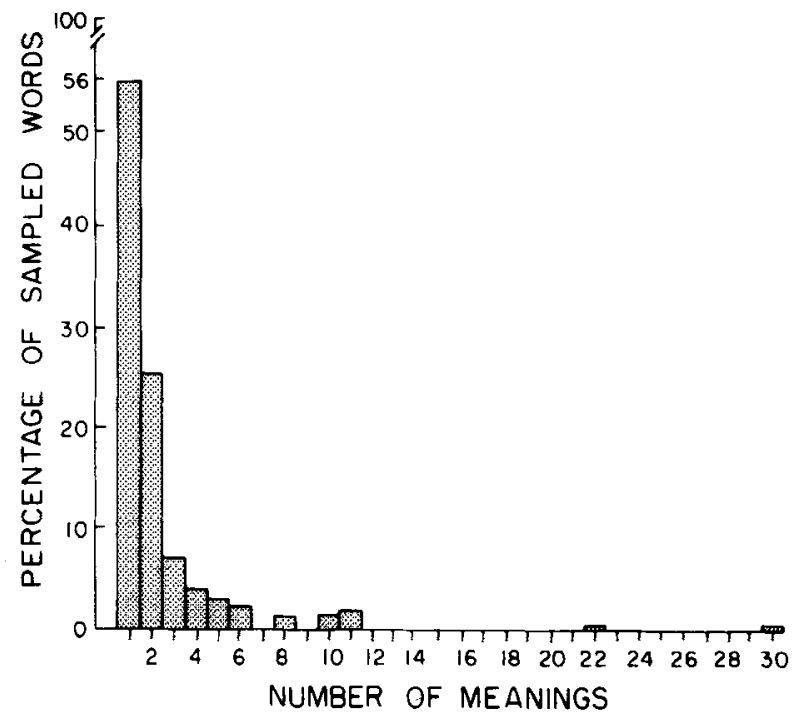

Figure 1. Distribution of number of dictionary meanings of a sample of English words. 
a sample do not reflect the ambiguity encountered under natural conditions. More accurate estimates can be obtained by giving greater weight to words that are most commonly used in discourse.

\section{STUDY 2}

The 100 most frequent English words account for $47 \%$ of the words occurring in written English (Kučera \& Francis, 1967). This is a substantial fraction of the words encountered by readers. In Study 2 , the lexical ambiguity of these words was determined by consulting dictionary definitions.

\section{Method}

The American Heritage Dictionary of the English Language (1969) was consulted to determine the number of meanings listed for the 100 most frequent English words. Several of the words were not listed separately: For example, "is," "was," "be," "are," "were," and "been" were all listed under "be." For words of this type, the number of meanings of the primary word was tabulated. Similar meanings were excluded, using a conservative criterion tending to reduce the number of meanings. Otherwise, the procedures were the same as for Study 1.

\section{Results and Discussion}

Table 1 shows the number of meanings recorded for each word. Figure 2 shows the distribution of the number of meanings per word, which range from 1 to 31 . The median is seven: $93 \%$ of the words have more than one meaning.

For each of the 100 most frequent words, Kučera and Francis (1967) report the absolute frequency. The 93 lexically ambiguous words account for 460,459 of the Kučera and Francis list of 1,014,232 words, or $45 \%$. Assuming that the Kucera and Francis sample is representative of words used in English text, at least $45 \%$ of the words that occur in text have more than one dictionary meaning.

Using a dictionary to determine the number of meanings may lead to an overestimate of the amount of lexical ambiguity that readers encounter. The dictionary includes many meanings that are rarely used and may not even be known to the average reader. In addition, distinctions between dictionary meanings are often very fine, perhaps finer than those used by most readers. A more conservative estimate of lexical ambiguity can be made by excluding meanings that occur very rarely, and by combining meanings that are similar.

\section{STUDY 3}

Some meanings of a word are used more often than others. Lorge and Thorndike (1938) report a semantic frequency count of the frequency of occurrence of each of the meanings of all words appearing in a 5-millionword sample of English text. The distinctions between meanings were based on the Oxford English Dictionary (1937). If a particular meaning did not occur in the

Table 1

Number of Meanings of the 100 Most Frequent English Words

\begin{tabular}{|c|c|c|c|}
\hline & & $\begin{array}{l}\text { Meanings } \\
\text { Counted }\end{array}$ & \\
\hline Rank & Word & Study 2 Study 3 & Study 4 \\
\hline
\end{tabular}

\begin{tabular}{|c|c|c|c|c|c|}
\hline & & & & & \\
\hline 1 & the & 8 & 3 & 1 & \\
\hline 2 & of & 18 & 8 & 1 & 2.96 \\
\hline 3 & and & 4 & 2 & 1 & 1.20 \\
\hline 4 & to & 21 & 9 & 3 & \\
\hline 5 & $\mathbf{a}$ & 5 & 3 & 1 & .36 \\
\hline 6 & in & 13 & 8 & 2 & \\
\hline 7 & that & 2 & 5 & 3 & \\
\hline 8 & is & $8(\mathrm{be})^{*}$ & 4 (be) & 1 & \\
\hline 9 & was & 8 (be) & 4 (be) & 1 & \\
\hline 10 & he & 2 & 1 & 1 & \\
\hline 11 & for & 28 & 8 & 1 & 2.95 \\
\hline 12 & it & 8 & 2 & 1 & .92 \\
\hline 13 & with & 26 & 5 & 1 & 2.52 \\
\hline 14 & as & 9 & 9 & 2 & \\
\hline 15 & his & 2 & 1 & 1 & \\
\hline 16 & on & 9 & 6 & 1 & 2.53 \\
\hline 17 & be & 8 & 4 & 1 & \\
\hline 18 & at & 13 & 5 & 1 & 2.47 \\
\hline 19 & by & 13 & 6 & 2 & \\
\hline 20 & 1 & 1 & 4 (me) & 1 & .82 \\
\hline 21 & this & 5 & 2 & 2 & \\
\hline 22 & had & 31 (have) & 5 (have) & 1 & 1.29 \\
\hline 23 & not & 1 & 1 & 1 & \\
\hline 24 & are & 8 (be) & 4 (be) & 1 & \\
\hline 25 & but & 9 & 2 & 1 & .59 \\
\hline 26 & from & 9 & 2 & 1 & 1.23 \\
\hline 27 & or & 3 & 2 & 1 & .16 \\
\hline 28 & have & 31 & 5 & 1 & 1.29 \\
\hline 29 & an & 1 & 3 (a) & 1 & .36 \\
\hline 30 & they & 3 & 1 & 1 & \\
\hline 31 & which & 6 & 2 & 1 & \\
\hline 32 & one & 7 & 5 & 1 & 2.24 \\
\hline 33 & you & 4 & 1 & 1 & \\
\hline 34 & were & 8 (be) & 4 (be) & 1 & \\
\hline 35 & her & 3 & 1 & 1 & \\
\hline 36 & all & 10 & 3 & 2 & \\
\hline 37 & she & 3 & 2 & 1 & .50 \\
\hline 38 & there & 4 & 4 & 1 & 1.30 \\
\hline 39 & would & 16 (will) & 5 (will) & 1 & 1.58 \\
\hline 40 & their & 1 & 2 & 2 & \\
\hline 41 & we & 4 & 1 & 1 & \\
\hline 42 & him & 6 & 1 (he) & $i$ & \\
\hline 43 & been & 8 (be) & 4 (be) & 1 & \\
\hline 44 & has & 31 (have) & 5 (have) & 1 & 1.29 \\
\hline 45 & when & 6 & 2 & 2 & \\
\hline 46 & who & 3 & 3 & 1 & \\
\hline 47 & will & 16 & 5 & 1 & 1.58 \\
\hline 48 & more & 2 & 1 & 2 & \\
\hline 49 & no & 3 & 1 & 2 & \\
\hline 50 & if & 4 & 4 & 1 & 1.16 \\
\hline 51 & out & 2 & 6 & 1 & 2.15 \\
\hline 52 & so & 8 & 4 & 2 & \\
\hline 53 & said & 1 & 2 (say) & 1 & .67 \\
\hline 54 & what & 3 & 4 & 3 & \\
\hline 55 & up & 17 & 7 & 2 & \\
\hline 56 & its & 2 & 1 & 1 & \\
\hline 57 & about & 8 & 3 & 2 & \\
\hline 58 & into & 7 & 2 & 1 & .92 \\
\hline 59 & than & 3 & 1 & 1 & \\
\hline 60 & them & 4 & 1 & 1 & \\
\hline 61 & can & 7 & 3 & 2 & \\
\hline 62 & only & 2 & 2 & 1 & .80 \\
\hline 63 & other & 7 & 2 & 1 & \\
\hline
\end{tabular}


Table 1 Continued

\begin{tabular}{|c|c|c|c|c|c|}
\hline \multirow{2}{*}{$\begin{array}{c}\text { Frequency } \\
\text { Rank }\end{array}$} & \multirow[b]{2}{*}{ Word } & \multicolumn{2}{|c|}{$\begin{array}{c}\text { Meanings } \\
\text { Counted }\end{array}$} & \multirow{2}{*}{$\begin{array}{l}\text { Parts of } \\
\text { Speech } \\
\text { Study } 4\end{array}$} & \multirow{2}{*}{$\begin{array}{l}\text { H Value } \\
\text { Study } 7\end{array}$} \\
\hline & & Study 2 S & Study $3 \mathrm{~S}$ & & \\
\hline 64 & new & 8 & 3 & 1 & .76 \\
\hline 65 & some & 4 & 2 & 2 & \\
\hline 66 & time & 16 & 5 & 1 & 2.44 \\
\hline 67 & could & 7 (can) & $3(\mathrm{can})$ & 2 & \\
\hline 68 & these & 5 (this) & 2 (this) & 2 & \\
\hline 69 & two & 2 & $2 \dagger$ & 1 & \\
\hline 70 & may & 7 & 4 & 1 & 1.68 \\
\hline 71 & then & 6 & 3 & 1 & .97 \\
\hline 72 & do & 16 & 8 & 1 & 2.23 \\
\hline 73 & first & 5 & 2 & 2 & \\
\hline 74 & any & 4 & 2 & 1 & 1.32 \\
\hline 75 & my & 3 & 2 & 1 & .57 \\
\hline 76 & now & 7 & 2 & 2 & \\
\hline 77 & such & 5 & 4 & 1 & 1.94 \\
\hline 78 & like & 8 & 3 & 3 & \\
\hline 79 & our & 1 & 1 & 1 & \\
\hline 80 & over & 15 & 4 & 2 & \\
\hline 81 & $\operatorname{man}$ & 15 & 6 & 2 & \\
\hline 82 & $\mathrm{me}$ & 6 & 4 & 1 & .82 \\
\hline 83 & even & 14 & 2 & 2 & \\
\hline 84 & most & 2 & 2 & 1 & 1.40 \\
\hline 85 & made & 4 & 7 (make & e) 2 & \\
\hline 86 & after & 15 & 5 & 3 & \\
\hline 87 & also & 1 & 1 & 2 & \\
\hline 88 & did & 16 (do) & 8 (do) & 1 & 2.23 \\
\hline 89 & many & 2 & 2 & 1 & 1.19 \\
\hline 90 & before & 9 & 2 & 3 & \\
\hline 91 & must & 6 & 2 & 1 & .67 \\
\hline 92 & $* * \mathrm{~F}$ & & & & \\
\hline 93 & through & 9 & 4 & 2 & \\
\hline 94 & back & 31 & 7 & 3 & \\
\hline 95 & years & 9 & 3 & 1 & .95 \\
\hline 96 & where & 4 & 2 & 1 & .75 \\
\hline 97 & much & 2 & 6 & 2 & \\
\hline 98 & your & 4 & 1 & 1 & \\
\hline 99 & way & 17 & 6 & 1 & 1.80 \\
\hline 100 & well & 12 & 5 & 2 & \\
\hline 101 & down & 15 & 4 & 3 & \\
\hline
\end{tabular}

Note-Words and frequency ranks were taken from Kučra and Francis (1967). In their table, the 92nd rank is occupied by nonword formulas. This rank was not considered in the analyses reported here. The 92nd rank was replaced by the word ranked 101 by Kucera and Francis. Because the nonword formulas were excluded, this table included the 100 most frequent words. The numbers of meanings counted for words in Study 2 were taken from the American Heritage Dictionary of the English Language; those for Study 3, and the numbers of parts of speech for words in Study 4, were taken from West (1953).

*Words in parentheses indicate the word listed in the second column did not appear as a separate entry in the dictionary. The word in parentheses is the word for which the number of meanings was recorded.

tThe word "two" was not listed by West (1953). The number of meanings and number of parts of speech shown here were taken from the American Heritage Dictionary listing.

sample, it was excluded from further analyses. This is the first of several sources of conservative bias in the estimates of lexical ambiguity to be presented here.

Lorge and Thorndike's (1938) data were used by West (1953) in preparing a semantic frequency count, in which the fine distinctions between meanings used in the Oxford English Dictionary were "grouped more coarsely" (West, 1953, p. vii). This was done by combining word meanings judged to be similar (West, 1953, p.xiii). West excluded meanings that occurred with very low frequency.

In making the count reported here, I excluded meanings that are idiomatic in the sense that the meaning depends on the word's appearance in a stereotyped phrase. The reason for this exclusion is that when the rest of the stereotyped phrase is present, the word is not ambiguous; when the phrase is not present, the idiomatic meaning does not come into play. These procedures should assure a relatively conservative estimate of the lexical ambiguity of the 100 most frequent English words.

\section{Method}

The 100 most frequent English words reported by Kučera and Francis (1967) were identified by West (1953), and the number of separate meanings for each word was tabulated. Idiomatic meanings were excluded. Some words were listed under other words; in these cases the number of meanings of the primary word was tabulated. Some examples of West's entries may be useful to convey the flavor of this little-known document. The word "by" is the 19th most frequent word in English text and is about .5\% of the words that appear in English text (Kučera \& Francis, 1967). The entry from West (1953) is shown in Table 2, along with the entries for "the" and "down," the most frequent and 100th most frequent words.

The first column lists the word and its parts of speech. The second column lists the meanings, numbered consecutively, with similar meanings given the same number but lettered consecutively. In the counts reported here, similar meanings were excluded. In the third column, examples of the usage are provided. In the fourth column, the percent of occurrences of each meaning is listed. These were not calculated by Lorge and Thorndike (1938) for "the."

\section{Results and Discussion}

Table 1 shows the number of meanings for each word. Figure 3 shows the frequency of the various numbers of meanings. The distribution is markedly less skewed than Figures 1 and 2. The number of meanings ranges from one to nine. The median is three, and there is more than one meaning for $85 \%$ of the words.

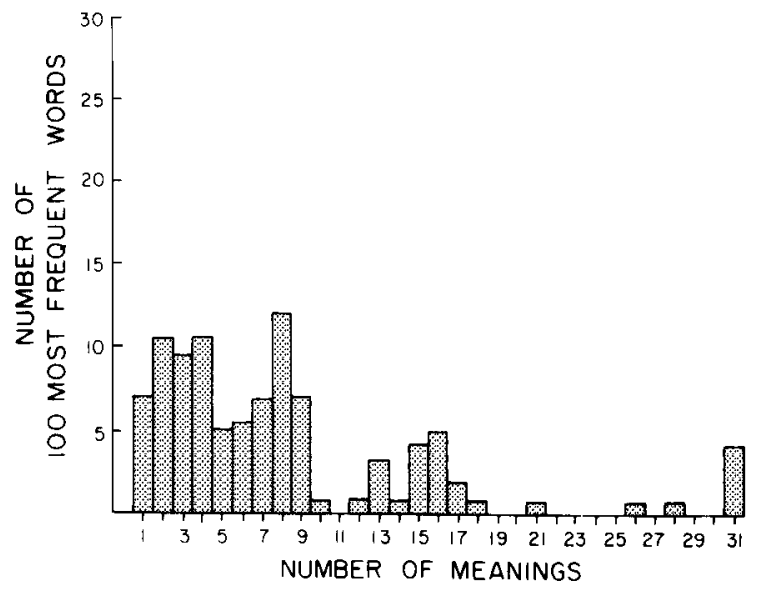

Figure 2. Distribution of number of dictionary meanings of the 100 most frequent English words. 
Table 2

Typical Entries From West (1953)

\begin{tabular}{|c|c|c|c|c|}
\hline Word & Part of Speech & Meaning & Examples of Usage & $\begin{array}{l}\text { Occur- } \\
\text { rence* }\end{array}$ \\
\hline \multirow[t]{9}{*}{ By } & \multirow[t]{8}{*}{ Preposition } & 1a position near & $\begin{array}{l}\text { Stand by his side; close by; I always keep some by me } \\
\text { (=in store). }\end{array}$ & \\
\hline & & lb motion near & Pass by your window; passed him by. & 5.6 \\
\hline & & 2 before & Do it by Wednesday. & 1.3 \\
\hline & & 3 during & By day; by night. & .4 \\
\hline & & 4 as a measure & $\begin{array}{l}\text { Paid by the hour; moved by inches; little by little; } \\
\text { strawberries by the handful; six feet long by four feet } \\
\text { wide; better by far. }\end{array}$ & 6.0 \\
\hline & & 5a instrument & $\begin{array}{l}\text { All due by kindness; worked by electricity; done by } \\
\text { mirrors; French by birth; lead by the hand; see by your } \\
\text { face; know you by your laugh; tell by looking at you; } \\
\text { send it by rail; multiply by } 10 \text {; live by writing. }\end{array}$ & \\
\hline & & $5 \mathrm{~b}$ instrument or cause & By reason of his ill temper, he lost the position. & 31.5 \\
\hline & & 6 agent & $\begin{array}{l}\text { Done by his agent; written by Shakespeare; proved by } \\
\text { time. }\end{array}$ & 48.0 \\
\hline & Adverb & & Stand by! A house nearby; I saw him pass by. & .8 \\
\hline \multirow[t]{4}{*}{ The } & \multirow[t]{4}{*}{ Definite Article } & $\begin{array}{l}\text { 1a denoting some particular } \\
\text { person or thing; "you } \\
\text { know the one I mean" }\end{array}$ & The man standing there (whom we saw yesterday, etc.). & \\
\hline & & $\begin{array}{l}\text { 1b denoting some well known } \\
\text { person or thing }\end{array}$ & The sun; the king. & $* *$ \\
\hline & & 2 used emphatically & The man for the job. & \\
\hline & & $\begin{array}{l}3 \text { used of a class, equivalent } \\
\text { to a plural. }\end{array}$ & The horse is an animal (=horses are animals). & \\
\hline \multirow[t]{5}{*}{ Down } & \multirow[t]{4}{*}{$\begin{array}{l}\text { Adverb and } \\
\text { Preposition }\end{array}$} & 1 to or in a lower position & $\begin{array}{l}\text { Let down (the cliff) on a rope; mud carried down by the } \\
\text { river; sit down, lie down, put down; the tide is down. }\end{array}$ & 54.0 \\
\hline & & 2 idea of illness or defeat & We are 14 points down in the game; down with influenza. & 24.0 \\
\hline & & $\begin{array}{l}3 \text { idea of lowness as on a } \\
\text { list or scale }\end{array}$ & $\begin{array}{l}\text { From the richest down to the poorest; prices marked } \\
\text { down; down to the present day. }\end{array}$ & 8.0 \\
\hline & & $\begin{array}{l}4 \text { idea of decrease of size } \\
\text { or activity }\end{array}$ & Grind down; wear down; calm down; die down. & 3.0 \\
\hline & Adjective & & The down train. & 6.0 \\
\hline
\end{tabular}

*Percent of occurrence with given meaning.

**Not calculated.

The 85 ambiguous words account for 434,100 of the million or so words, or $43 \%$. Thus, at least $43 \%$ of the words in English text are lexically ambiguous, even when quite conservative procedures are used to determine whether a word has more than one meaning.

It may be argued that some lexical ambiguity can be resolved by certain grammatical mechanisms. It is possible to refine the estimate to take this possibility into account.

\section{STUDY 4}

Some of the 100 most frequent words have meanings in two or more different parts of speech. In these cases, the sentence frame in which the word appears might allow the reader to exclude one part of speech because of grammatical constraints, and all the meanings associated with that part of speech could be ignored, assuming that the grammatical constraints operated prior to semantic ones.

For words with more than one part of speech, part or all of the ambiguity might be resolved by grammatical

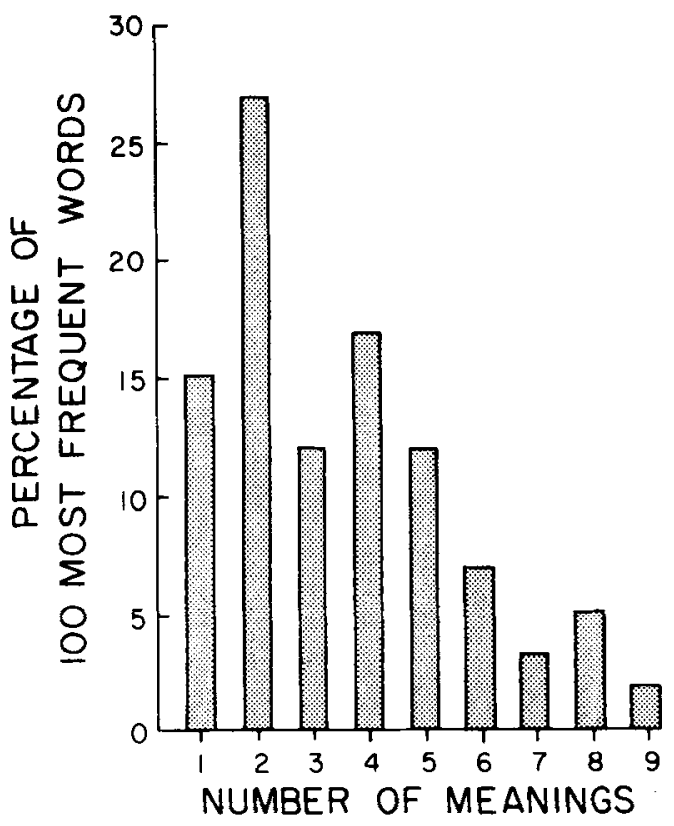

Figure 3. Distribution of number of meanings of the 100 most frequent English words with rare and idiomatic meanings excluded and similar meanings combined. 
calculations, without recourse to semantics. For ambiguous words with only one part of speech, grammatical considerations of this type cannot be used to resolve the ambiguity. In Study 4 the number of parts of speech of each word was determined.

\section{Method}

For each of the 100 most frequent words, the number of parts of speech was determined by consulting West (1953). The resulting data were entered into Table 1 .

\section{Results and Discussion}

Table 3 shows the proportions of the 100 most frequent words in the various categories. For words with multiple meanings and only one part of speech, the ambiguity cannot be resolved even partially by determining the part of speech. For these words, ambiguity must be resolved semantically or by separate grammatical means. These constitute $32 \%$ of the words used in English text and this figure is the lowest estimate of amount of lexical ambiguity. This is an appreciable fraction of the words that language processors encounter.

Words with only one meaning and one part of speech are not lexically ambiguous. These constitute at least 4\% of the words used in English text, an appreciable fraction of the words encountered by readers.

For words with one meaning but more than one part of speech, ambiguity is grammatical, that is, the part of speech of the word is uncertain. These constitute less than $1 \%$ of the language.

\section{STUDY 5}

Whenever a pronoun occurs, the reader must supply the referent if it is to be understood correctly. Pronouns thus constitute a class of words that are essentially ambiguous. In Study 5 a lower bound for the frequency of this type of ambiguity was determined.

\section{Method}

The frequency of occurrence of the 15 pronouns represented among the 100 most frequent words was determined from Kucera and Francis (1967).

\section{Results and Discussion}

Pronouns constitute 56,748 of the words in Kucera and Francis' (1967) sample, or some 6\% of English text.

Table 3

Proportions of 100 Most Frequent Words With One or More Than One Meanings or Parts of Speech

\begin{tabular}{lrccc}
\hline & \multicolumn{3}{c}{ Number of Meanings } \\
\cline { 2 - 5 } Number of & \multicolumn{2}{c}{ One } & \multicolumn{2}{c}{ More Than One } \\
\hline One & 12 & $(4 \%)$ & 54 & $(32 \%)$ \\
More Than One & 3 & $(1 \%)$ & 31 & $(12 \%)$ \\
\hline
\end{tabular}

Note-Percentages indicate proportion of words used in English text constituted by these words.
Pronouns provide a situation where the "context," which is so often implicated in discussions of the resolution of ambiguity, is unitary (the referent) and is limited to a particular verbal unit whose location in time and space is known. Presumably, the mental operations involved in remembering a definite referent can be brought under experimental scrutiny easily, because the referent can be precisely specified and controlled.

\section{STUDY 6}

Quite apart from the meanings specified in dictionaries, authors and speakers often define special or restricted meanings for important words on the occasion of their first occurrence in a passage. When this occurs, the reader or listener is expected to recover the previously specified meaning if the word occurs again later. In Study 6 the frequency in English prose of this form of lexical ambiguity was determined.

\section{Method}

A sample of English prose was selected from the list of nonfiction documents provided by Kucera and Francis (1967). The list is a representative sample of English prose used in their analyses. A total of 26 documents were specified by Kucera and Francis (1967), with sufficient bibliographic information to enable an individual to locate them in a library. Of these only 16 were obtainable at the University of Iowa and in local libraries in Iowa City, Iowa. These were examined for exemplars of special purpose definitions according to two criteria: (1) The word was defined by the document's author in a special or restricted sense that differed from any of the meanings provided in the American Heritage Dictionary of the English Language (1969); and (2) the term was used repeatedly later in the passage in the special or restricted sense. I made the first judgments Then, Professor James V. Hinrichs of the Department of Psychology at the University of Iowa made independent judgments for each document. The results include only those exemplars on which both judges agreed.

\section{Results and Discussion}

Among the 16 documents, 5 contained clear exemplars of special purpose definitions (Ashford, 1961; Driver, 1961; Fulbright, 1961; Miller, 1961; Vedder, 1965). The characteristics of these can best be expressed by example. In Fulbright (1961), the term "community" is defined as "a feeling and deep conviction of shared values and interests, a feeling that effective communication is possible, a feeling of trust and confidence in each other's purpose" (p. 3-4), and later used repeatedly in that sense, "such a community," "a genuine community," "a limited community," and so on.

In Ashford (1961) the term "commune" is defined in the third sentence of the article as "the basic unit of local reform." This definition does not appear in the dictionary; in fact, it is quite remote from any of the dictionary meanings. The first later use of the term is "Preparations for elections began slightly more than a year after independence with the first steps to organize rural communes" (p. 2). Since none of the dictionary 
definitions make reference to elections in relation to communes, a reader who used only a dictionary definition would have difficulty understanding the relation between elections and communes. The meaning would be clear to a reader who remembered the special purpose definition of "commune."

About $30 \%$ of the documents examined in this study contained exemplars of special purpose definitions. It appears that such definitions are relatively common in English text. Informal observations suggest that readers are able to cope with them without difficulty.

The import of Studies 5 and 6 is that word meanings need not be permanently engraved into semantic memory in order to function effectively in language processing. Temporary word meanings are routinely established to function during small segments of a passage, as in the case of pronouns, or for larger units of text including whole passages. The relative ease with which such temporary meanings can be established, utilized, and abandoned suggests that semantic memory and the associated processing mechanisms may be more flexible and labile than present conceptions imply.

\section{STUDY 7}

The measure of lexical ambiguity used in the preceding studies was the number of meanings. In Study 7 a more refined measure is proposed that takes into account the frequency of the different meanings.

This measure is $\mathrm{H}=-\mathrm{p}_{\mathrm{i}} \log _{2} \mathrm{P}_{\mathrm{i}}$, the Shannon-Wiener measure of average uncertainty of information (Attneave, 1959). As applied to word meanings, it is a measure of semantic uncertainty. To apply this measure, it is necessary to know the probability $\left(\mathrm{P}_{\mathrm{i}}\right)$ of the different alternative outcomes in a situation. This information was provided for word meanings by West (1953).

\section{Method}

Of the 100 most frequent words, 12 are not lexically or grammatically ambiguous and 3 are grammatically but not lexically ambiguous. These words, constituting $5 \%$ of the words used in English text, have no semantic uncertainty: $\mathbf{H}=0$.

of the remaining 85 words, 31 have more than one meaning and some semantic uncertainty, but they also are of more than one part of speech, and are thus grammatically ambiguous as well. The relative contributions of semantic and grammatical features to the uncertainty of words are beyond the scope of this paper, and these words were not considered further.

There remain the 54 words that have more than one meaning but only one part of speech; these constitute about $32 \%$ of the words used in English text. Of these, the frequencies of the different meanings are not listed by West (1953) for the words "the," "who," "which," "other," "two," and "be" and the forms of "be": "is," "are," "was," "were," and "been." These constitute $11 \%$ of the words used in English, leaving $21 \%$ for the remaining 42 words.

For each of these 42 words, the frequency of the different meanings was determined from West (1953). In most cases the frequencies reported (as percentages) by West did not sum to $100 \%$. The missing information represented the meanings that had been excluded by Lorge and Thorndike (1938), or by West, as too rare. The logic of $\mathrm{H}$ requires that the probabilities sum to 1. Therefore, the residual percentage was calculated and added as a single additional meaning. For each word, the $H$ value was computed using tables of $-\mathrm{p}_{\mathbf{i}} \log _{2} \mathrm{P}_{\mathbf{i}}$ (Alluisi, 1965).

\section{Results and Discussion}

Figure 4 shows the distribution of $\mathrm{H}$ values for the 42 words considered in this analysis. For comparison, the letters a through $h$ are placed below the scale, representing the $\mathrm{H}$ value of a hypothetical word with only one meaning (a), two equiprobable meanings (b), three equiprobable meanings (c), and so on, up to a word with eight equiprobable meanings $(\mathrm{h})$. The median $\mathrm{H}$ value of the 42 words is 1.23 .

\section{GENERAL DISCUSSION}

At least $32 \%$ of the words that occur in English text are lexically ambiguous by the conservative criteria used in Study 4. This estimate is an extreme lower bound for the amount of lexical ambiguity in English text, because only 54 of the 100 most frequent English words are considered. Inclusion of the remaining 200,000 or so words would contribute additional ambiguity. So an appreciable fraction of the words used in English text are ambiguous.

Nevertheless, it could be argued that lexical ambiguity is relatively unimportant in text processing. One argument is that lexical ambiguities are resolved by prior context before the ambiguous word occurs, so that only one of the meanings is activated. But Foss and Jenkins (1973) found that ambiguity influenced processing even when a disambiguating prior context was present. Also, even if prior context did exclude one meaning, more than one meaning may be left; as Study 3 shows, most ambiguous words have three or more meanings.

Another argument is that grammatical ambiguity is more common than lexical ambiguity. Without a quantitative estimate of the amount of grammatical ambiguity, this argument is difficult to justify.

With respect to the relative importance of lexical

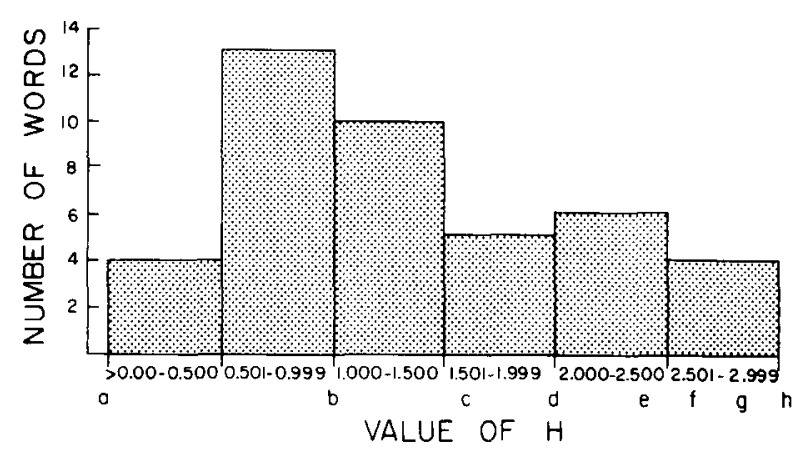

Figure 4. Distribution of semantic uncertainty or information value for the 100 most frequent English words (exclusions described in text). 
and grammatical ambiguity, consider the outcomes of the six experiments in which both lexical and grammatical ambiguities were presented to subjects (Bever, Garrett, \& Hurtig, 1973; Foss, 1970; Foss, Bever, \& Silver, 1968; MacKay, 1966; MacKay \& Bever, 1967; Mistler-Lachman, 1972). All but one found effects for both lexical and grammatical ambiguities (Bever et al., 1973; cf. Hogoboam \& Perfetti, 1975). These results do not support the hypothesis that grammatical ambiguities are more important than lexical ambiguities.

\section{REFERENCES}

AlluisI, E. A. Tables of binary logarithms, uncertainty functions, and binary $\log$ functions. Perceptual and Motor Skills, 1965, 20, 1005-1012.

The American heritage dictionary of the English language. Boston, Mass: Houghton Mifflin, 1969.

Ashford, D. E. Elections in Morocco: Progress or confusion. The Middle East Journal, 1961, 15, 1-15.

AtTneave, F. Applications of information theory to psychology. New York: Henry Holt, 1959.

Bever, T. G., Garrett, M. F., \& Hurtig, R. The interaction of perceptual processes and ambiguous sentences. Memory \& Cognition, 1973, 1, 277-286.

Driver, T. F. Beckett by the Madeleine. Columbia University Forum, 1961, Summer, 21-25.

Foss, D. J. Some effects of ambiguity upon sentence comprehension. Journal of Verbal Learning and Verbal Behavior, 1970, 9, 699.706.

Foss, D. J., Bever, T. G., \& Silver, M. The comprehension and verification of ambiguous sentences. Perception \& Psychophysics, 1968, 4, 304-306.
Foss, D. J., \& Jenkins, C. M. Some effects of context on the comprehension of ambiguous sentences. Journal of Verbal Learning and Verbal Behavior, 1973, 12, 577-589.

Fulbright, J. W. For a concert of free nations. Foreign Affairs, 1961, 40, 1-18.

GARRETT, M. F. Does ambiguity complicate the perception of sentences. In G. B. Flores d'Arcais and W. J. M. Levelt (Eds.), Advances in psycholinguistics. Amsterdam: North Holland Publishing, 1970.

Hogoboam, T. W., \& Perfetti, C. A. Lexical ambiguity and sentence comprehension. Journal of Verbal Learning and Verbal Behavior, 1975, 14, 265-274.

Kú́era, H., \& Francis, W. N. Computational analysis of present-day American English. Providence, R.I: Brown University Press, 1967.

LORGE, I., \& ThORNDike, E. L. A semantic count of English words. New York: The Institute of Educational Research, Teachers College, Columbia University, 1938.

MacKay, D. G. To end ambiguous sentences. Perception \& Psychophysics, 1966, 2, 193-200.

MacKay, D. G., \& Bever, T. G. In search of ambiguity. Perception \& Psychophysics, 1967, 2, 193-200.

Miller, A. S. Toward a concept of national responsibility. Yale Review, 1961, 51, 185-193.

Mistler-LachmaN, J. L. Levels of comprehension in processing of normal and ambiguous sentences. Journal of Verbal Learning and Verbal Behavior, 1972, 11, 614-623.

Oxford English Dictionary. Oxford, England: Oxford University Press, 1937.

VEDDER, J. F. Micrometeroids in satellite environmental handbook. Stanford, Calif: Stanford University Press, 1965.

WEST, M. A general service list of English words. London, England: Longmans, Green, 1953.

(Received for publication April 19, 1977; revision accepted September 29, 1977.) 